\title{
Atividade antioxidante e correlações com componentes bioativos de produtos comerciais de cupuaçu
}

\author{
Antioxidant activity and correlations with bioactive components from \\ commercial products of cupuaçu
}

\author{
Gerusa Matias Santos ${ }^{\mathrm{I}}$ Geraldo Arraes Maia ${ }^{{ }^{*}}$ Paulo Henrique Machado Sousa ${ }^{\text {II }}$ \\ Raimundo Wilane Figueiredo ${ }^{\mathrm{I}}$ José Maria Correia Costa ${ }^{\mathrm{I}}$ \\ Ana Valquíria Vasconcelos Fonseca ${ }^{\mathrm{I}}$
}

\section{RESUMO}

O cupuaçu é considerado um importante fruto tipicamente amazônico e apresenta polpa ácida, agradável e de aroma característico. Esses atributos de qualidade o colocam no ranking das exportações de frutas. No Brasil, o cupuaçu é consumido principalmente na forma de polpa congelada. Os estudos com marcas comerciais de polpa de cupuaçu que correlacionaram a atividade antioxidante aos níveis de compostos bioativos mostraram que a capacidade de sequestro de espécies radicalares, pelo método do radical ABTS, apresentou correlação positiva com os compostos fenólicos e não com os carotenoides e a vitamina C. Porém, todas as marcas avaliadas apresentaram diferenças significativas quanto aos teores de vitamina $C$, carotenoides e capacidade antioxidante total equivalente ao trolox.

Palavras-chave: Theobroma grandiflorum, compostos fenólicos, carotenóides, vitamina $C$, atividade antioxidante, ABTS.

\section{ABCTRACT}

The cupuaçu is considered an important Amazonic fruit, which presents acidic pulp, pleasant and characteristic flavor. This quality attributes places the cupuaçu in the ranking of exporting fruits. In Brazil, the cupuaçu is mostly consumed as frozen pulps. Studies with cupuaçu pulp brands correlated antioxidant activity with the levels of bioactive compounds and showed that antioxidant activity carried out through the ABTS radical presented a positive correlation only with the phenolic compounds and not with carotenoids and vitamin C. However, all the evaluated brands showed significant differences in the levels of vitamin $C$, carotenoids and trolox total equivalent antioxidant capacity.

Key words: Theobroma grandiflorum, phenolic compounds, carotenoids, vitamin $C$, antioxidant activity, ABTS.

\section{INTRODUÇÃO}

A combinação existente entre a enorme variedade de frutas tropicais passíveis de exploração e desenvolvimento no Brasil, bem como o crescimento do consumo interno e externo de sucos e polpas, têm aumentado a oportunidade de produção e exportação de sucos e polpas pelo país (MAIA et al., 2007).

$\mathrm{O}$ mercado de polpas de frutas congeladas teve um crescimento razoável nos últimos anos e, com a variedade de frutas e sabores exóticos, torna-se uma boa alternativa, principalmente com relação às exportações. Porém, devido à inexistência de padrões para todos os tipos de frutas, encontram-se no mercado produtos sem uniformidade (BUENO et al., 2002). Dentre essas frutas, encontra-se o cupuaçu (Theobroma grandiflorum Shum), um dos mais importantes frutos tipicamente amazônicos. O cupuaçu é uma fruta originaria do sul e sudeste da Amazônia (LANNES, 2003). O cupuaçu é apreciado por sua polpa ácida e de aroma intenso. Devido ao seu sabor forte, a

'Departamento de Tecnologia de Alimentos, Universidade Federal do Ceará (UFC), 60356-000, Fortaleza, CE, Brasil. E-mail: gmaia@secrel.com.br. * Autor para correspondência.

"Instituto de Cultura e Arte, Gastronomia, UFC, Fortaleza, CE, Brasil. 
polpa dos frutos não é normalmente consumida sozinha, mas é utilizada para fabricação de bebidas ("vinho do cupuaçu" e suco), sorvetes, licores, geleias, conservas e doces (BASTOS et al., 2002; YANG et al., 2003).

Além de atender aos padrões exigidos pela legislação vigente, é interessante, para a indústria de alimentos, que estes possuam propriedades que melhorem a sua funcionalidade, assim como o aumento nos componentes bioativos, sendo muito deles antioxidantes. Antioxidantes são compostos que atuam inibindo e/ou diminuindo os efeitos desencadeados pelos radicais livres (SOARES et al., 2005), podendo ser definidos como compostos que protegem as células contra os efeitos danosos dos radicais livres oxigenados e nitrogenados, formados nos processos oxidativos. Os radicais livres em excesso geram um desbalanço, dando início ao estresse oxidativo, processo metabólico responsável pelo desencadeamento de diversos tipos de doenças crônico-degenerativas. Os antioxidantes podem ser obtidos por meio da ingestão de alimentos, destacandose as vitaminas $\mathrm{E}$ e $\mathrm{C}$, os carotenoides, os compostos fenólicos, entre outros (ALI et al., 2008).

Em razão das grandes perspectivas de mercado nacional e internacional com relação ao consumo da polpa de cupuaçu, este trabalho teve por objetivo verificar o potencial antioxidante em diversas marcas de polpa dessa fruta. Mais especificamente, foram observados a atividade antioxidante total, os níveis de compostos fenólicos e o teor de carotenoides e vitamina $\mathrm{C}$.

\section{MATERIAL E MÉTODOS}

Material

Foram empregadas como matéria-prima polpas de cupuaçu de sete marcas comerciais, sendo seis polpas não diluídas e uma adicionada de conservantes (sorbato de potássio e metabissufito) e sacarose; um suco integral, adicionado de conservantes; e um suco pronto para beber adicionado de conservantes. Foram coletadas três repetições de cada amostra e estas foram avaliadas em triplicata.

Determinações físico-químicas

$\mathrm{O} \mathrm{pH}$ foi medido por meio de leitura direta em potenciômetro (HANNA INSTRUMENTS, modelo HI 9321); mediu-se a acidez total (AT) por titulometria com $\mathrm{NaOH} 0,1 \mathrm{M}$ segundo método descrito na AOAC (2000), e os resultados foram expressos em \% de ácido cítrico. Os sólidos solúveis totais (SST) $\left({ }^{\circ} \mathrm{Brix}\right)$ foram medidos por meio da leitura direta em um refratômetro digital portátil (ATAGO, modelo PAL-1 $\left.\left(20^{\circ} \mathrm{C}\right)\right)$. Os açúcares redutores (AR) e totais (AT) foram quantificados pela metodologia de MILLER (1959), que utiliza o ácido 3,5-dinitro-salicílico (DNS) e a leitura da absorbância a 540nm, com o auxílio de um espectrofotômetro UV-VIS (Micronal, modelo B 582). Os valores foram expressos em \% de glicose. A intensidade de cor foi feita por meio da quantificação, em solução etanólica, dos pigmentos solúveis, de acordo com RATTANATHAANALERK et al. (2005). Foram utilizados $10 \mathrm{~mL}$ de amostra para $40 \mathrm{~mL}$ da mistura água:etanol (1:3). O homogenato foi centrifugado a 3000 rpm, por 10 minutos, e os extratos brutos submetidos à leitura em espectrofotômetro a 420nm. A atividade de água $\left(\mathrm{a}_{\mathrm{w}}\right)$ foi medida em aparelho Aqualab CX-2 Decagon, a $25^{\circ} \mathrm{C}$.

Determinações de ácido ascórbico, compostos fenólicos, carotenoides e atividade antioxidante

A determinação de ácido ascórbico foi realizada segundo a AOAC (2000), modificada por ASSUNÇÃO \& MERCADANTE (2003), utilizando ácido oxálico $1 \%$ com extrator e reduzindo o indicador 2,6-diclorobenzenoindofenol (DCFI) pelo ácido ascórbico. A concentração de ácido ascórbico foi determinada com uma curva-padrão de ácido Lascórbico.

Os carotenoides totais foram determinados pelo método de HIGBY (1962), cuja extração ocorreu por meio da agitação da amostra com álcool e hexano, com três filtrações posteriores. As leituras foram realizadas em espectrofotômetro UV-VIS a 450nm, e os resultados foram expressos em $\mathrm{mg}$ de carotenoides totais/100g de amostra.

Os compostos fenólicos totais foram determinados de acordo com o método colorimétrico de Folin-Denis, utilizando-se curva-padrão de ácido tânico (AOAC, 1980).

A atividade antioxidante foi determinada pelo método do ABTS (Re et al., 1999), com algumas modificações. O radical cátion ABTS (ABTS•+) foi gerado por meio da reação de $5 \mathrm{~mL}$ de solução aquosa de ABTS $(7 \mathrm{mM})$ e persulfato de potássio $(2,45 \mathrm{mM})$. A mistura permaneceu no escuro, a $29^{\circ} \mathrm{C}$, por 14 horas, e só depois foi diluída com etanol até absorbância de $0,7 \pm 0,02$ a $734 \mathrm{~nm}$, com o auxílio de um espectrofotômetro UV-VIS. Uma amostra de $30 \mu \mathrm{L}$ do extrato das frutas e do antioxidante-padrão Trolox e da vitamina $\mathrm{C}$, tomados como referência, reagiu com $3 \mathrm{~mL}$ da solução resultante do radical ABTS no escuro. O decréscimo da absorbância a $734 \mathrm{~nm}$ foi medido após seis minutos. A curva-padrão foi linear entre $500-1500 \mu \mathrm{M}$ de Trolox e 0-20mg de ácido ascórbico/100mL. Os resultados foram 
expressos em $\mu \mathrm{M}$ de capacidade antioxidante equivalente ao Trolox (TEAC), por grama de massa fresca, e em mg de atividade antioxidante equivalente ao ácido ascórbico (VCEAC), por 100g de massa fresca. As diluições das polpas utilizadas no presente estudo foram: 1:0;1:1;1:2 e 1:3. Essa análise não foi realizada nas marcas que possuíam conservantes.

\section{Análise estatística}

Realizaram-se análise de variância e teste de Tukey $(a=5 \%)$ para testar a diferença entre os resultados, e realizou-se correlação de Pearson para determinar a correlação entre os componentes bioativos e a atividade antioxidante, sendo utilizado o programa estatístico SAS (Statistical Analyses System), versão 9.1 (SAS, 2006). A análise estatística foi aplicada somente para a comparação dos resultados das polpas de cupuaçu não diluídas e sem conservantes.

\section{RESULTADOS E DISCUSSÃO}

A análise de variância demonstrou diferenças estatísticas entre as polpas de cupuaçu integrais para todos os parâmetros avaliados $(\mathrm{P}<0,05)$. Não foi verificada diferença significativa para atividade de água $\left(\mathrm{a}_{\mathrm{w}}\right)$, segundo teste de Tukey, a $5 \%(\mathrm{P}>0,05)$ (Tabela 1). De acordo com os dados da Tabela 1, o pH das polpas integrais das marcas 2,3 e 6 não apresentaram diferenças significativas; a acidez total titulável apresentou semelhança entre as marcas 1 e 5 $(\mathrm{P}<0,05)$. Entretanto, com relação aos sólidos solúveis, as marcas 1,2 e $3 ; 1$ e 5 , e 4 e 6 foram semelhantes entre si. Já a relação de semelhança nos açúcares totais foi entre as marcas 1, 2 e 3, e 3 e 5; já nos açúcares redutores as semelhanças foram entre as marcas 1 e 5 , e 4 e 6 . Somente a marca 6 apresentou diferença significativa entre as médias do parâmetro cor.
Verificou-se que todas as marcas apresentaram pH menor que 4,00 (Tabela 1), sendo classificados como muito ácidos. De acordo JAY (2005), os alimentos são classificados como de baixa acidez ( $\mathrm{pH}>4,50)$, ácidos ( $\mathrm{pH}$ de 4,00 a 4,50) e muito ácidos $(\mathrm{pH}<4,00)$. Essa classificação se baseia no $\mathrm{pH}$ mínimo para a multiplicação e produção de toxina do Clostridium botulinum $(4,50)$ e para a multiplicação da grande maioria das bactérias $(4,00)$. Segundo ensaios dessa análise, não foram observados riscos de desenvolvimento de toxinas desse grupo de bactérias ou de outras patogênicas.

Resultados semelhantes de $\mathrm{pH}$ foram observados por SCHWAN et al. (2000), BUENO et al. (2002) e COSTA et al. (2003), os quais, ao estudarem polpa de cupuaçu, encontraram valor de $\mathrm{pH}$ de 3,3. Todas as polpas avaliadas estavam de acordo com a legislação em vigor, cujo valor mínimo de $\mathrm{pH}$ estipulado é de 2,6 (MAPA, 2000).

A acidez total titulável das amostras de polpas integrais variou de 1,28 a 2,31\% de ácido cítrico (Tabela 1), enquanto o menor valor encontrado, de $0,37 \%$ de ácido cítrico, foi para o suco pronto para beber, possivelmente devido à menor quantidade de polpa neste produto e consequentemente maior teor de água. A acidez total titulável encontrada neste trabalho foi semelhante aos valores de acidez encontrados por CALZAVARA et al. (1984), que observaram $2,15 \%$ de acidez para o fruto de cupuaçu, e de SCHWAN et al. (2000), que quantificaram acidez de $2,22 \%$. BUENO et al. (2002), ao estudarem a polpa de cupuaçu, verificaram valor de acidez de $1,90 \%$, e COSTA et al. (2003) encontraram acidez de 2,27\%. De acordo com a legislação (MAPA, 2000), o valor mínimo de acidez para polpa de cupuaçu é de $1,50 \%$ de ácido cítrico. Com base nos valores encontrados neste estudo, as polpas integrais das marcas 3 e 6 e a polpa

Tabela 1 - Parâmetros químicos e físico-químicos dos produtos de cupuaçu estudados.

\begin{tabular}{|c|c|c|c|c|c|c|c|}
\hline Amostras & $\mathrm{pH}$ & ATT & SST & AT & AR & Cor & $a_{w}$ \\
\hline Polpa 1 & $3,51 \pm 0,00^{\mathrm{b}}$ & $1,54 \pm 0,01^{\mathrm{d}}$ & $8,60 \pm 0,00^{\text {bc }}$ & $5,34 \pm 0,06^{\mathrm{c}}$ & $3,85 \pm 0,05^{\mathrm{a}}$ & $0,07 \pm 0,00^{\mathrm{b}}$ & $0,94 \pm 0,01^{\mathrm{a}}$ \\
\hline Polpa 2 & $3,41 \pm 0,00^{\mathrm{c}}$ & $1,62 \pm 0,01^{\mathrm{c}}$ & $8,55 \pm 0,21^{\mathrm{c}}$ & $5,40 \pm 0,08^{\mathrm{c}}$ & $2,86 \pm 0,12^{\mathrm{b}}$ & $0,07 \pm 0,00^{\mathrm{b}}$ & $0,96 \pm 0,01^{\mathrm{a}}$ \\
\hline Polpa 3 & $3,39 \pm 0,02^{\mathrm{c}}$ & $1,28 \pm 0,01^{\mathrm{e}}$ & $7,60 \pm 0,28^{\mathrm{c}}$ & $5,20 \pm 0,01^{\mathrm{cd}}$ & $1,32 \pm 0,01^{\mathrm{d}}$ & $0,07 \pm 0,00^{\mathrm{b}}$ & $0,98 \pm 0,01^{\mathrm{a}}$ \\
\hline Polpa 4 & $3,24 \pm 0,00^{\mathrm{d}}$ & $2,25 \pm 0,02^{\mathrm{b}}$ & $11,65 \pm 0,49^{\mathrm{a}}$ & $7,45 \pm 0,11^{\mathrm{a}}$ & $2,04 \pm 0,13^{\mathrm{c}}$ & $0,07 \pm 0,00^{b}$ & $0,98 \pm 0,01^{\mathrm{a}}$ \\
\hline Polpa 5 & $3,72 \pm 0,02^{\mathrm{a}}$ & $1,52 \pm 0,01^{\mathrm{d}}$ & $9,85 \pm 0,35^{\mathrm{b}}$ & $4,90 \pm 0,05^{\mathrm{d}}$ & $3,50 \pm 0,14^{\mathrm{a}}$ & $0,07 \pm 0,00^{\mathrm{b}}$ & $0,94 \pm 0,02^{\mathrm{a}}$ \\
\hline Polpa 6 & $3,36 \pm 0,02^{\mathrm{c}}$ & $2,31 \pm 0,00^{\mathrm{a}}$ & $12,75 \pm 0,35^{\mathrm{a}}$ & $6,81 \pm 0,19^{b}$ & $2,24 \pm 0,06^{\mathrm{c}}$ & $0,12 \pm 0,01^{\mathrm{a}}$ & $0,97 \pm 0,00^{\mathrm{a}}$ \\
\hline Suco Integral & $3,40 \pm 0,00$ & $1,16 \pm 0,00$ & $4,45 \pm 0,07$ & $2,81 \pm 0,01$ & $2,63 \pm 0,06$ & $0,04 \pm 0,00$ & $0,99 \pm 0,00$ \\
\hline Suco pronto para beber & $3,70 \pm 0,00$ & $0,37 \pm 0,03$ & $11,80 \pm 0,00$ & $11,67 \pm 0,16$ & $7,22 \pm 0,06$ & $0,02 \pm 0,00$ & $0,99 \pm 0,01$ \\
\hline Polpa + conservante + sacarose & $3,44 \pm 0,00$ & $1,37 \pm 0,02$ & $5,20 \pm 0,00$ & $3,32 \pm 0,06$ & $2,85 \pm 0,08$ & $0,05 \pm 0,00$ & $0,99 \pm 0,01$ \\
\hline
\end{tabular}

ATT: Acidez Total Titulável (\% ác. cítrico); SST: Sólidos Solúveis Totais ( ${ }^{\circ}$ Brix); AT: Açúcares Totais (\%); AR: Açúcares Redutores (\%); $\mathrm{a}_{\mathrm{w}}$ : atividade de água.

Médias seguidas de mesma letra, nas colunas, não diferem significativamente entre si pelo teste de Tukey, a $5 \%$. 
adicionada de conservantes e sacarose não se encontram de acordo com os padrões propostos pela legislação.

Os sólidos solúveis totais ( $\mathrm{SST}$ ) das marcas de cupuaçu (Tabela 1 ) variaram de 4,45 a $12,75^{\circ}$ Brix. Um dos maiores valores de SST encontrados foi o do suco pronto para beber. A polpa integral da marca 6 apresentou o valor mais alto $\left(12,75^{\circ} \mathrm{Brix}\right)$ entre as polpas integrais de cupuaçu. Isso pode ser justificado pelo possível grau de pureza da polpa, uma vez que a adição de água parece reduzir a concentração dos sólidos solúveis. O menor valor encontrado de SST ( ${ }^{\circ}$ Brix) foi para o suco integral, o que pode ser um indício de diluição desse produto. Segundo a legislação brasileira (MAPA, 2000), os sólidos solúveis para a polpa de cupuaçu devem possuir valor mínimo de $9,00^{\circ}$ Brix. Os dados encontrados neste trabalho (Tabela 1) mostraram que somente as polpas das marcas 4, 5 e 6 estiveram dentro das normas preconizadas pela legislação. As diferenças entre os resultados encontrados para as marcas podem ter sido ocasionadas pela adição de água às polpas, bem como pelas possíveis diferenças entre os frutos utilizados. Vários são os fatores que podem alterar a concentração de sólidos solúveis, como o tipo de cultivo, o solo, a época de colheita, o clima e as diferenças pluviométricas durante a colheita (BUENO et al., 2002). Resultados semelhantes aos resultados de algumas marcas do presente estudo foram encontrados por BUENO et al. (2002), que observaram valores de SST de $8,20^{\circ}$ Brix, e COSTA et al. (2003), que encontraram SST de $12,5^{\circ}$ Brix para a polpa de cupuaçu.

Os açúcares totais variaram de 4,90 a 7,45\% de glicose entre as polpas sem adição de sacarose (Tabela 1). De acordo com resultados da tabela 1, o suco pronto para beber foi o que apresentou maior teor sacarose, o que sugere a hipótese de uma possível adição desse sacarídeo ao produto processado. A polpa adicionada de conservantes e sacarose não apresentou valor de açúcar total elevado, provavelmente pela possível diluição. A legislação brasileira (MAPA, 2000) estipula que o valor mínimo de açúcares totais para a polpa de cupuaçu é de $6,00 \mathrm{~g} 100 \mathrm{~g}^{-1}$. De acordo com esse valor, somente as polpas integrais 4 e 6 encontramse de acordo com os parâmetros da legislação. BUENO et al. (2002) justificam que o valor de açúcares totais inferior ao estabelecido pela legislação pode ser devido à porcentagem maior de umidade da polpa.

Os teores de açúcares redutores (Tabela 1) encontrados para as polpas variaram entre 1,32 e 7,22\% de glicose. $\mathrm{O}$ néctar de cupuaçu foi o material que apresentou o maior conteúdo de açúcares redutores, o que pode ser explicado pela possível hidrólise da sacarose, que ocorre principalmente na etapa de pasteurização do produto. Resultados superiores foram encontrados por BUENO et al. (2002) (4,7\%) e CALZAVARA et al. (1984) (9,09\%). Entretanto, SCHWAN et al. (2000) encontraram menores teores $(1,85 \%)$ em comparação aos observados neste estudo.

Os produtos de cupuaçu apresentaram variação de cor de 0,02 a 0,12 (420nm) (Tabela 1). A polpa de cupuaçu apresentou valores inferiores na cor, que podem ser justificados pela própria característica da polpa da fruta, a qual possui coloração branca a branca amarelada; ou pela possível diluição desse produto.

Os valores de atividade de água nas polpas analisadas de cupuaçu foram similares aos encontrados por COSTA et al. (2003). À medida que a atividade de água decresce, a estabilidade e a segurança dos alimentos aumentam, pois esta influencia a multiplicação, atividade metabólica, resistência e sobrevivência dos microorganismos presentes. Contudo, a atividade de água depende da concentração de sólidos solúveis ( ${ }^{\circ}$ Brix) do produto (SOUZA FILHO et al., 1999).

Verificou-se diferença significativa, em torno de $5 \%$, no conteúdo de vitamina $\mathrm{C}$, nas polpas integrais de cupuaçu. Os valores de ácido ascórbico das polpas

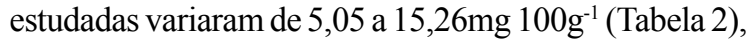
sendo os teores desse componente baixos quando comparados com outras frutas tropicais. SCHWAN et al. (2000) encontraram valor de ácido ascórbico total de $12,60 \mathrm{mg} 100 \mathrm{~g}^{-1}$ para polpa de cupuaçu, semelhante ao encontrado em algumas marcas deste estudo. Valores superiores foram encontrados por BUENO et al. (2002) $\left(25,80 \mathrm{mg}\right.$ de ácido ascórbico $\left.100 \mathrm{~g}^{-1}\right)$ para essas polpas. O MAPA (2000) estipula valores mínimos de $18,00 \mathrm{mg} .100 \mathrm{~g}^{-1}$. De acordo com esse valor, todas as polpas encontram-se à margem dos parâmetros propostos pela legislação. Esses resultados podem ter sido ocasionados pela instabilidade do ácido ascórbico durante o armazenamento ou processamento e/ou pela possível adulteração das polpas por meio da adição de água.

Os menores valores de vitamina C encontrados foram das amostras de suco pronto para

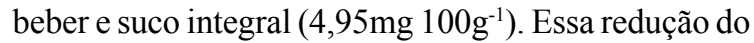
conteúdo de vitamina $\mathrm{C}$ pode ser atribuída ao tratamento térmico durante o processamento dos sucos (VIEIRA et al., 2000). O teor de vitamina C pode ser influenciado pelo tipo de solo, pela forma de cultivo, pelas condições climáticas e pelas práticas de póscolheita e armazenamento (SOUZA FILHO et al., 1999; CHITARRA \& CHITARRA, 2005).

Os conteúdos de carotenoides totais variaram de 0,02 a $0,99 \mathrm{mg}$ de carotenóides $100 \mathrm{~g}^{-1} \mathrm{de}$ 
polpa (Tabela 2). Esses valores de carotenoides eram esperados, uma vez que a coloração da polpa de cupuaçu não está dentro da faixa de cor dos carotenoides, que variam do amarelo ao vermelho (MAIA et al., 2007). SENTANIN \& RODRIGUEZAMAYA (2007), avaliando os conteúdos de carotenoides em algumas cultivares de pêssegos, observaram níveis muito baixos que também estavam correlacionados à coloração semelhante à da polpa de cupuaçu.

Os valores de compostos fenólicos variaram de 10,85 a 74,90mg de ácido tânico $100 \mathrm{~g}^{-1}$ de polpa fresca (Tabela 2). KUSKOSKI et al. (2006) encontraram valor de fenóis totais de $20,50 \pm 3,0 \mathrm{mg}$ de ácido gálico em $100 \mathrm{~g}^{-1}$ de peso fresco, para polpa de cupuaçu, resultado inferior ao encontrado nas polpas deste estudo e semelhante ao de suco integral.

Os potenciais antioxidantes dos produtos de cupuaçu variaram de 1,11 a $1,57 \mu \mathrm{M}$ de Trolox $\mathrm{g}^{-1} \mathrm{de}$ peso fresco e em atividade antioxidante equivalente à vitamina C (VEAC) de 14,33 a 36,14mg de ácido ascórbico $100 \mathrm{~g}^{-1}$ de peso fresco (Tabela 2). Esses valores foram baixos quando comparados com outras frutas, como a graviola e o açaí, avaliadas por KUSKOSKI et al. (2005), que estudaram a atividade antioxidante de 11 polpas diferentes. Esses autores obtiveram valores para a polpa de cupuaçu entre $1,70 \pm 0,1$ e 2,00 $\pm 0,1$ ( $\mu \mathrm{M}$ de Trolox $\mathrm{g}^{-1}$ de peso fresco) com o mesmo método. Os valores encontrados pelos autores mostraram que o cupuaçu foi classificado como o fruto de menor capacidade antioxidante entre as 11 polpas estudadas.
Não se verificou correlação de Pearson entre os valores de atividade antioxidantes expressas em TEAC e VEAC ( $\mathrm{r}=0,40 ; \mathrm{P}>0,05)$. Somente os compostos fenólicos apresentaram correlação significativa positiva $(\mathrm{r}=0,79 ; \mathrm{P}<0,05)$ com a atividade antioxidante em relação ao TEAC das polpas de cupuaçu integrais; porém, não foi observada correlação com ácido ascórbico $(\mathrm{r}=-0,36 ; \mathrm{P}>0,05)$ e carotenoides $(\mathrm{r}=0,06$; $\mathrm{P}>0,05$ ). GARDNER et al. (2000) também verificaram correlação desprezível para carotenoides $(\mathrm{r}=-0,03)$, enquanto os compostos fenólicos $(\mathrm{r}=0,97)$ foram os principais contribuintes na atividade antioxidante em sucos de frutas não cítricas.

Diante da falta de padronização e de acordo com os resultados encontrados, acredita-se que a criação de padrões de identidade e qualidade para produtos de cupuaçu será de grande importância para os consumidores e para as indústrias de processamento de cupuaçu.

\section{CONCLUSÃO}

Este estudo mostrou que as polpas de cupuaçu das marcas avaliadas estavam em desacordo com a legislação em pelo menos um dos parâmetros de qualidade ( $\mathrm{pH}$, acidez, açúcares totais e vitamina $\mathrm{C}$ ). Os valores de carotenoides e a atividade antioxidante para os produtos de cupuaçu foram baixos quando comparados com o de outras frutas. A capacidade antioxidante das polpas foi correlacionada com o teor de fenólicos totais; porém, a vitamina $\mathrm{C}$ e os carotenoides pouco contribuíram para a capacidade sequestrante de radicais livres.

Tabela 2 - Componentes bioativos dos produtos de cupuaçu estudados.

\begin{tabular}{|c|c|c|c|c|c|}
\hline \multirow{2}{*}{ Amostras } & \multirow{2}{*}{$\begin{array}{l}\text { Vitamina C } \\
\left(\mathrm{mg} 100 \mathrm{~g}^{-1}\right)\end{array}$} & \multirow{2}{*}{$\begin{array}{c}\text { Carotenoides } \\
\left(\mathrm{mg} 100 \mathrm{~g}^{-1}\right)\end{array}$} & \multicolumn{2}{|c|}{-------Atividade antioxidante-------- } & \multirow{2}{*}{ Fenólicos (mg de ác. Tânico $\left.100 \mathrm{~g}^{-1}\right)$} \\
\hline & & & TEAC & VEAC & \\
\hline Polpa 1 & $7,35 \pm 3,15^{b}$ & $0,17 \pm 0,02^{\mathrm{c}}$ & $1,33 \pm 0,02^{\mathrm{b}}$ & $34,76 \pm 0,25^{\mathrm{a}}$ & $53,75 \pm 0,49^{\mathrm{bc}}$ \\
\hline Polpa 2 & $5,05 \pm 0,01^{\mathrm{b}}$ & $0,23 \pm 0,08^{\mathrm{bc}}$ & $1,57 \pm 0,08^{\mathrm{a}}$ & $34,02 \pm 0,62^{\mathrm{a}}$ & $74,90 \pm 3,39^{\mathrm{a}}$ \\
\hline Polpa 3 & $15,26 \pm 0,13^{\mathrm{a}}$ & $0,16 \pm 0,10^{\mathrm{c}}$ & $1,11 \pm 0,05^{\mathrm{c}}$ & $30,17 \pm 4,82^{\mathrm{a}}$ & $51,85 \pm 1,20^{\mathrm{c}}$ \\
\hline Polpa 4 & $7,17 \pm 2,38^{b}$ & $0,92 \pm 0,02^{\mathrm{ab}}$ & $1,12 \pm 0,07^{\mathrm{c}}$ & $24,96 \pm 1,98^{\mathrm{b}}$ & $60,90 \pm 1,56^{\mathrm{abc}}$ \\
\hline Polpa 5 & $11,83 \pm 0,93^{\mathrm{ab}}$ & $0,99 \pm 0,32^{\mathrm{a}}$ & $1,54 \pm 0,02^{\mathrm{a}}$ & $36,14 \pm 0,33^{\mathrm{a}}$ & $67,44 \pm 2,60^{\mathrm{ab}}$ \\
\hline Polpa 6 & $11,25 \pm 0,96^{\mathrm{ab}}$ & $0,74 \pm 0,29^{\text {abc }}$ & $1,33 \pm 0,02^{\mathrm{b}}$ & $14,33 \pm 0,41^{\mathrm{c}}$ & $63,12 \pm 7,41^{\mathrm{abc}}$ \\
\hline Suco Integral & $4,95 \pm 0,00$ & $0,05 \pm 0,04$ & $\mathrm{Nd}$ & $\mathrm{Nd}$ & $28,00 \pm 0,00$ \\
\hline Suco pronto para beber & $4,95 \pm 0,00$ & $0,02 \pm 0,01$ & $\mathrm{Nd}$ & $\mathrm{Nd}$ & $10,85 \pm 0,07$ \\
\hline Polpa + conservante + sacarose & $9,90 \pm 0,00$ & $0,12 \pm 0,00$ & $\mathrm{Nd}$ & $\mathrm{Nd}$ & $31,50 \pm 1,13$ \\
\hline
\end{tabular}

Nd - Não determinado. TEAC - Atividade antioxidante equivalente ao Trolox ( $\mu \mathrm{M} / \mathrm{g}$ de Trolox). VEAC - Atividade antioxidante equivalente ao ácido ascórbico $\left(\mathrm{mg} 100 \mathrm{~g}^{-1}\right)$.

Médias seguidas de mesma letra, nas colunas, não diferem significativamente entre si pelo teste de Tukey, a 5\%.

Ciência Rural, v.40, n.7, jul, 2010. 


\section{REFERÊNCIAS}

ALI, S.S. et al. Indian medicinal herbs as sources of antioxidants. Food Research International, v.41, n.1, p.115, 2008. Disponível em: <http://dx.doi.org/10.1016/ j.foodres.2007.10.001>. Acesso em: 20 maio, 2010. doi:10.1016/j.foodres.2007.10.001.

AOAC - Association of Official Analytical Chemists. Official Methods of Analysis of the AOAC international. 17.ed. Gaithersburg, Maryland, 2000. 1200p.

AOAC - Association of Official Analytical Chemists. Official Methods of Analysis of the AOAC international. 12.ed. Washington, DC, 1980. 61p.

ASSUNÇÃO, R.B.; MERCADANTE, A.Z. Carotenoids and ascorbic acid from cashew apple (Anacardium occidentale L.): variety and geographic effects. Food Chemistry, v.81, n.4, p.495-502, 2003. Disponível em: <http://dx.doi.org/10.1016/ S0308-8146(02)00477-6>. Acesso em: 20 maio, 2010. doi:10.1016/S0308-8146(02)00477-6.

BASTOS, M.S.R. et al. Efeito da aplicação de enzimas pectinolíticas no rendimento da extração de polpa de cupuaçu. Revista Brasileira de Fruticultura, v.24, n.1, p. 240242, 2002. Disponível em: <http://dx.doi.org/10.1590/S010029452002000100051>. Acesso em: 20 maio, 2010. doi: $10.1590 / \mathrm{S} 0100-29452002000100051$.

BUENO, S.M. et al. Avaliação da qualidade de polpas de frutas congeladas. Revista do Instituto Adolfo Lutz, v.62, n.2, p.121-126, 2002. Disponível em: <http:// biblioteca.ial.sp.gov.br/index.php?option=com_remosit ory $\&$ Itemid $=27 \&$ func $=$ fileinfo $\& i d=306>$. Acesso em: 20 maio, 2010 .

CHITARRA, M.I.F.; CHITARRA, A.B. Pós-colheita de frutos e hortaliças: fisiologia e manuseio. 2.ed. Lavras: UFLA, 2005. 785p.

COSTA, M.C. et al. Conservação de polpa de cupuaçu [Theobroma gradiflorum (Willd. Ex Spreng.) Schum] por métodos combinados. Revista Brasileira de Fruticultura, v.25, n.2, p.213-215, 2003. Disponível em: $<$ http://dx.doi.org/ 10.1590/S0100-29452003000200007>. Acesso em: 20 maio, 2010. doi: 10.1590/S0100-29452003000200007.

GARDNER, P.T. et al. The relative contributions of vitamin $\mathrm{C}$, carotenoids and phenolics to the antioxidant potential of fruit juices. Food Chemistry, v.68, n.4, p.471474, 2000. Disponível em: <http://dx.doi.org/10.1016/S03088146(99)00225-3>. Acesso em: 20 maio, 2010. doi:10.1016/ S0308-8146(99)00225-3.

HIGBY, W.K. A simplified method for determination of some the carotenoid distribution in natural and carotene - fortified orange juice. Journal of Food Science, v.27, n.1, p.42-49, 1962. Disponível em: <http://dx.doi.org/10.1111/j.13652621.1962.tb00055>. Acesso em: 20 maio, 2010. doi: 10.1111/ j.1365-2621.1962.tb00055.
JAY, J.M. Microbiologia de alimentos. 6.ed. Porto Alegre: Artmed, 2005. $711 \mathrm{p}$.

KUSKOSKI, E.M. et al. Frutos tropicais silvestres e polpas de frutas congeladas: atividade antioxidante, polifenóis e antocianinas. Ciência Rural, v.36, n.4, p.1283-1287, 2006. Disponível em: <http://dx.doi.org/10.1590/S010384782006000400037>. Acesso em: 20 maio, 2010. doi: $10.1590 / \mathrm{S} 0103-84782006000400037$

KUSKOSKI, E.M. et al. Aplicacion de diversos métodos químicos para determinar actividad antioxidant en pulpa de frutos. Ciência e Tecnologia de Alimentos, v.25, n.4, p.726732, 2005. Disponível em: <http://dx.doi.org/10.1590/S010120612005000400016>. Acesso em: 20 maio, 2010. doi: 10.1590/S0101-20612005000400016.

LANNES, S.C.S. et al. Cupuassu - A new confectionery fat from Amazonia. Inform-AOCS, v.14, n.1, p.40-41, 2003.

MAIA, G.A. et al. Processamento de sucos de frutas tropicais. Fortaleza: UFC, 2007. 320p.

MAPA - Ministério da Agricultura, Pecuária e Abastecimento. Brasil. Instrução Normativa n.01 de 07 de janeiro de 2000. Aprovar o Regulamento Técnico Geral para fixação dos Padrões de Identidade e Qualidade para polpa de fruta. Diário Oficial da União, 10 jan. 2000.

MILLER, G.L. Use of dinitrosalicilic acid reagent for determination of reducing sugar. Analytical Chemistry, v.31, n.3, p.426-428, 1959. Disponível em: <http://pubs.acs.org/ doi/abs/10.1021/ac60147a030>. Acesso em 21 maio, 2010. doi: $10.1021 / \mathrm{ac} 60147 \mathrm{a} 030$

YANG, H. et al. New bioactive polyphenols from Theobroma grandiflorum ("Cupuaçu"). Journal of Natural Products, v.66, n.11, p.1501-1504, 2003. Disponível em: <http:// pubs.acs.org/doi/full/10.1021/np034002j>. Acesso em 21 maio, 2010. doi: $10.1021 / \mathrm{np} 034002 \mathrm{j}$

RATTANATHAANALERK, M. et al. Effects of thermal processing on the quality loss of pineapple juice. Journal of Food Engineering, v.66, n.2, p.259-265, 2005. Disponível em: <http://dx.doi.org/10.1016/j.jfoodeng.2004.03.016>. Acesso em 21 maio, 2010. doi: 10.1016/j.jfoodeng.2004.03.016.

RE, R. et al. Antioxidant activity applying an improved ABTS radical cation decolorization assay. Free Radical Biology \& Medicine, v.26, n.9-10, p.1231-1237, 1999. Disponível em: <http://dx.doi.org/10.1016/S08915849(98)00315-3>. Acesso em: 20 maio, 2010. doi: 10.1016/ S0891-5849(98)00315-3.

SAS INSTITUTE. SAS software, version 9.1. Cary, 2006. $176 \mathrm{p}$.

SCHWAN, R.F. et al. Cupuaçu [Theobroma grandiflorum (Willd Ex Spreng.)]. In: ALVES, R.E.; FILGUEIRAS, H.A.C.; MOURA, C.F.H. Caracterização de frutas nativas da América Latina. Jaboticabal: FUNEP, 2000. Cap.8, p.31-34. (Série Frutas Nativas, 9).

Ciência Rural, v.40, n.7, jul, 2010. 
SENTANIN, M.A.; RODRIGUEZ-AMAYA, D.B. Teores de carotenóides em mamão e pêssego determinados por cromatografia líquida de alta eficiência. Ciência e Tecnologia de Alimentos, v.27, n.1, p.13-19, 2007. Disponível em: <http:/ /dx.doi.org/ 10.1590/S0101-20612007000100003>. Acesso em: 20 maio, 2010. doi: 10.1590/S0101-20612007000100003.

SOARES. D.G. et al. Avaliação de compostos com atividade antioxidante em células da levedura Saccharomyces cerevisiae. Revista Brasileira de Ciências Farmacêuticas, v.41, n.1, p.95-100, 2005. Disponível em: <http://dx.doi.org/10.1590/ S1516-93322005000100011>. Acesso em: 20 maio, 2010. doi: $10.1590 / \mathrm{S} 1516-93322005000100011$.
SOUZA FILHO, M.S.M. et al. Efeito do branqueamento, processo osmótico, tratamento térmico e armazenamento na estabilidade da vitamina $\mathrm{C}$ de pedúnculos de caju processados por métodos combinados. Ciência e Tecnologia de Alimentos, v.19, n.2, p.211-213, 1999. Disponível em: <http:/ /dx.doi.org/10.1590/S0101-20611999000200010>. Acesso em: 20 maio, 2010. doi: 10.1590/S0101-20611999000200010.

VIEIRA, M.C. et al. Mathematical modeling of the thermal degradation kinetics of vitamin $\mathrm{C}$ in cupuaçu (Theobroma grandiflorum) nectar. Journal of Food Engineering, v.43, n.1, p.1-7, 2000. Disponível em: <http://dx.doi.org/10.1016/ S0260-8774(99)00121-1>. Acesso em: 20 maio, 2010. doi:10.1016/S0260-8774(99)00121-1. 